\title{
Technical performance assessment of phase change material components
}

\author{
Ana Lazaro ${ }^{1}$, Monica Delgado ${ }^{1}$, Andreas König-Haagen ${ }^{2}$, Stephan Höhlein ${ }^{2}$, Gonzalo Diarce ${ }^{3}$ \\ ${ }^{1}$ Aragón Institute for Engineering Research (I3A), Thermal Engineering and Energy Systems Group, \\ University of Zaragoza, Zaragoza (Spain) \\ ${ }^{2}$ Chair of Engineering Thermodynamics and Transport Processes (LTTT), Center of Energy \\ Technology (ZET), University of Bayreuth, Bayreuth (Germany) \\ ${ }^{3}$ University of the Basque Country - UPV/EHU, ENEDI research group, Dpto. de Máquinas y Motores \\ Térmicos, Escuela de Ingeniería de Bilbao Bilbao (Spain)
}

\begin{abstract}
Thermal energy storage systems using phase change materials (PCM) should meet the application requirements in terms of technical and economical parameters. The storage capacity and storage density are the two main parameters for the selection of a suitable storage material. However, among the technical parameters, high thermal power is one of the most challenging characteristics for a PCM thermal storage. Most of the materials currently used as PCM have intrinsically low thermal conductivity; therefore, the component design has to compensate this. This paper presents a definition of a set of parameters to describe PCM heat exchangers in terms of capacity and density. Furthermore, a power performance assessment is proposed based on the analysis of the results obtained for different storage systems based on the same geometry. A validated numerical model is used to assess the suitability of the proposed parameters to compare PCM systems with different configurations and operation conditions. The influence of Biot number, Stefan number, HTF volume and NTU (varied by different mass flows) on the proposed parameters is studied.
\end{abstract}

Keywords: Thermal Energy Storage, Phase Change Material, performance, power, overall heat transfer coefficient

\section{Introduction}

Thermal energy storage based on liquid-solid phase change materials is considered as a key technology for the integration of renewable energy sources. The storage capacity and storage density are the two main parameters for the selection of a suitable storage material. However, not only the capacity, but also the thermal response of the system during charging and discharging must fit the application requirements. Among the technical parameters, high thermal power is one of the most challenging characteristics for a PCM thermal energy storage; however, most of the currently used PCMs have intrinsically low thermal conductivity. Thus, this shortage has to be compensated by a proper component design.

The traditional approach to face this challenge has relied on the simulation of several design options until an adequate solution is achieved, which is time consuming. Furthermore, the new literature developments/results are rarely presented based on standardized parameters. Consequently, the comparison of the performance of systems published in different sources cannot be done directly or, sometimes, is not even possible. Kalapala \& Devanuri (2018) reviewed more than 150 references found in literature on the influence of design parameters and operational conditions (mass flow and inlet temperature) on the performance of latent heat exchangers. The parameters used in the comparison are the energy stored, melting fraction over time, charging/discharging periods and heat transfer rate. Performance is assessed according to these parameters. The results are not 
comparable between different geometries, not even between the same geometries studied by different authors. Fornarelli et al. (2019) numerically studied the influence of the geometry on the heat transfer in a latent heat storage where the PCM volume and the heat transfer surface are kept identical. The thermal performance of the two geometries is compared in terms of complete melting times. Another recent example can be found in Zondag et al, (2018). In this work a shell and tubes latent heat exchanger is investigated and a lab prototype PCM thermal storage is experimentally tested. The results are shown as overall thermal power output over time, time dependent thermal power and state of phase. Delgado et al. (2015) compared the technical performance of PCM slurries heat exchangers with the information provided in literature and highlighted the difficulties to estimate common performance parameters. Pinnau (2009) compared different latent thermal energy storage systems in terms of storage density (more specific the actual storage density related to the theoretical maximum) and a normed power. Later on Brüggemann et al. (2017) compared their results to the one of Pinnau (2009).

Alternatively, a proper understanding of the influence that the geometry and configuration have on the performance of PCM components could aid during the design stage. This could be based on a deeper analysis of response curves obtained from experimental tests. Unfortunately, since various key properties, such as temperature, PCM effective heat capacity, density and viscosity are not constant over the charging and discharging processes, the heat exchanger performance shows a transient nature. Therefore, as it is deeply justified in Groulx (2018), conventional heat exchanger analysis ( $\varepsilon$-NTU, LMTD) is not directly suitable for the performance assessment. Unlike steady state heat exchanger analysis, transient heat exchanger analysis is very complex. Some references (Gao et al (2015). and Amagour et al. (2018)) present the transient heat transfer effectiveness $\varepsilon(t)$ as a performance parameter for the evaluation of heat exchangers under unsteady-state condition. Analytic solution, CFD and experimental characterization are the approaches adopted. In those cases, the non-steady state conditions are due to a change in the temperature at the inlet or a variation of the HTF mass flow over time. In any of them non-steady state conditions are inevitably caused by the change of the overall heat exchange coefficient (U) over time. Nevertheless, some examples of $\varepsilon$-NTU approach applied to PCM heat exchangers are found in literature. Ismail et al. (1999) present a performance study based on dimensionless numbers for PCM heat exchangers. In this study, the efficiency is defined based on a ideal heat exchange during charging assuming the PCM temperature at the higher temperature over the melting temperature range. Numerical results show the proposed parameters: solidified mass fraction, NTU and effectiveness over dimensionless time for different Biot numbers and dimensionless radio. Belusko et al. (2012) applied this methodology to the flat plate geometry. In this study, the sensible heat contribution was ignored and the effectiveness is defined as in boiling or condensation processes, assuming a uniform PCM temperature. Effectiveness is then compared over the phase change for different Reynolds and for two different fluids (water and air). In this work, authors highlight the difficulty to define the temperature for the $\varepsilon$-NTU methodology $n$ PCM heat exchangers. Ma et al.(2018) proposed dimensionless design parameters of a one-tank thermocline heat storage system based on the effectiveness-number of transfer units method. In this work, the actual heat exchanged is evaluated using an outlet temperature of the HTF estimated as an average over time. However, no unified procedure that allows a proper comparison of the response curves of PCM components has been developed up to date.

There are also other previous works that have dealt with this issue: various technical parameter definitions can be found in Rojas et al. (2011) and Romani et al. (2018). However, the overall comparison in terms of power and capacity aimed in this work is not completed in those approaches.

Accordingly, as an initial step to advance towards generally applicable performance parameters, it is herein intended to compare the experimental response curves of several PCM components developed by various laboratories and for different applications. This paper presents a definition of a set of parameters to describe PCM heat exchangers in terms of capacity and density. Furthermore, a power performance assessment is proposed based on the analysis of the results obtained for different storage systems based on the same geometry. A validated numerical model is used to assess the most adequate evaluation of the proposed parameters. The concluding recommendations would be used for the further development of the methodology within the working group PCM of the IEA SHC-ECES Task58-Annex 33 (http://task58.iea-shc.org/) on compact energy storage. 


\section{Methodology}

2.1 PCM components and experimental setups

Among the existing geometries and configurations of PCM components, flat plate geometry was selected for this study. The PCM is enclosed within plates that show prismatic shapes. These containers can present different aspect ratios and they might be arranged vertically or horizontally. The HTF flows through the outer part of the plates, so an external shell is needed to encompass both the PCM plates and the HTF. The external shell is assumed to be adiabatic except for the validation of the numerical model where heat losses are taken into account.

The main characteristics of the PCM components studied are: i) system A consists of 14 hollow aluminum prismatic plates containing PCM. The plates are placed parallelly and separated by small aluminum strips. The HTF channels are formed by the space that the plates leave between them. The HTF is water with a mass flow of $2.4 \mathrm{~kg} / \mathrm{min}$. PCM thickness is $16 \mathrm{~mm}$ and it contains $11.8 \mathrm{~kg}$ of commercial PCM, Rubitherm RT60. ii) system B is a real scale PCM-air heat exchanger where the PCM is encapsulated in aluminum flat plates. Air mass flow is $1.68 \mathrm{~kg} / \mathrm{min}$, PCM thickness is $5 \mathrm{~mm}$ and contains $135 \mathrm{~kg}$ of commercial PCM Rubitherm, RT27.

The two experimental setups used for the model validation and comparison of results consist of closed loops. The mass flow, inlet and outlet temperatures of the HTF are registered. The HTF inlet temperature can be controlled and successive charging and discharging cycles can be set up.

\subsection{Performance parameters}

A selection of suitable parameters for the assessment of PCM components for TES systems was first performed. The technical parameters are defined in two categorical groups: capacity and power.

\section{Capacity}

The capacity parameters were selected based on a performed literature review and they are shown in table 1 . The parameter descriptions and required calculation steps found in literature were discussed and completed when considered necessary. Following the obtained procedure, a capacity assessment of different TES laboratory-scale prototypes previously realised by the authors in their respective institutions was performed.

Tab. 1: Capacity performance parameters proposal for PCM thermal energy storage systems.

\begin{tabular}{|c|c|c|c|c|c|}
\hline & Parameter & Definition/calculation & Units & Additional information & Reference \\
\hline \multirow[t]{2}{*}{ Capacity } & $\begin{array}{l}\text { Energy } \\
\text { storage } \\
\text { capacity of } \\
\text { the system }\end{array}$ & $\mathrm{ESC}_{\mathrm{sys}}=\mathrm{ESC}_{\mathrm{mat}}+\mathrm{ESC}_{\mathrm{comp}}$ & $\mathrm{kJ}$ or $\mathrm{MJ}$ & $\begin{array}{l}\text { Temperature range [Tmax,Tmin] } \\
\mathrm{ESC}_{\text {mat }}=\mathrm{m}_{\text {mat }} \cdot \Delta \mathrm{h}_{\text {mat }} \\
\mathrm{ESC}_{\text {comp }}=\mathrm{m}_{\text {comp }} \cdot \Delta \mathrm{h}_{\text {comp }} \\
\Delta \mathrm{h}: \text { Enthalpy variation within the } \\
\text { temperature range }\end{array}$ & $\begin{array}{l}\text { [ Romani } \\
\text { et al. 2018] }\end{array}$ \\
\hline & $\begin{array}{l}\text { Energy } \\
\text { storage } \\
\text { density }\end{array}$ & $\mathrm{ESC}_{\mathrm{sys}} / \mathrm{V}$ & $\begin{array}{l}\mathrm{kJ} / \mathrm{m}^{3} \text { or } \\
\mathrm{MJ} / \mathrm{m}^{3}\end{array}$ & $\begin{array}{l}\mathrm{V} \text { : Total volume of the heat exchanger, } \\
\text { considering insulation and vessel }\left(\mathrm{m}^{3}\right)\end{array}$ & \\
\hline
\end{tabular}

Power

Three different approaches were attempted to evaluate the power performance of the systems. First the power performance was assessed by comparison of the heat exchange over time. This approach is simple and straightforward, because it only requires inlet and outlet temperatures and mass flow rate data to achieve an initial estimation. However, the results are dependent on the system size, HTF temperature and operating conditions. Therefore, two other approaches are proposed - an overall heat exchange coefficient $(\mathrm{U} \cdot \mathrm{A}$, denoted as UA $[\mathrm{W} / \mathrm{K}]$, defined as the inverse of the overall heat exchanger resistance) and a normalized power $\dot{Q}_{\text {norm }}$ $\left[\mathrm{W} /\left(\mathrm{m}^{3} \cdot \mathrm{K}\right)\right]$.

The exchanged energy can be evaluated applying an energy balance to the heat transfer fluid (assuming no phase change in the HTF) as described in fluid (eq. 1). Attending to the heat transfer between two bounded streams, the evaluation of the $\mathrm{UA}[\mathrm{W} / \mathrm{K}]$ is proposed in equation 2 . The average temperature difference between 
the two streams (HTF and PCM) is defined in equations 3-5.

$$
\begin{aligned}
& \dot{\mathrm{Q}}(\mathrm{t})=\dot{\mathrm{m}}_{\mathrm{HTF}} \cdot \mathrm{c}_{\mathrm{HTF}} \cdot\left(\mathrm{T}_{\mathrm{HTF}, \text { in }}-\mathrm{T}_{\mathrm{HTF}, \text { out }}(\mathrm{t})\right) \text { (eq. 1) } \\
& \dot{\mathrm{Q}}(\mathrm{t})=\mathrm{UA} \cdot \overline{\Delta \mathrm{T}_{\mathrm{m}}} \text { (eq. 2) } \\
& \overline{\Delta \mathrm{T}_{\mathrm{m}}}=\frac{\Delta \mathrm{T}_{2}-\Delta \mathrm{T}_{1}}{\ln \left(\frac{\Delta \mathrm{T}_{2}}{\Delta \mathrm{T}_{1}}\right)} \text { (eq. 3) } \\
& \Delta \mathrm{T}_{1}=\mathrm{T}_{\mathrm{HTF}, \text { in }}-\overline{\mathrm{T}}_{\text {ref, } 1} \text { (eq. 4) } \\
& \Delta \mathrm{T}_{2}=\mathrm{T}_{\mathrm{HTF}, \text { out }}(\mathrm{t})-\overline{\mathrm{T}}_{\text {ref,2 }} \text { (eq. 5) }
\end{aligned}
$$

Due to the transient process and the non-uniform temperature distribution along the heat exchanger, the proper evaluation of the average temperature difference is essential. Thus, the most adequate definition of reference temperatures $T_{\text {ref }}$ is investigated. In this study, six different alternatives were defined and studied as reference temperatures, divided in turn into three different groups, as follows.

A first group comprises temperatures that can be assumed as a single value for the PCM temperature at the HTF

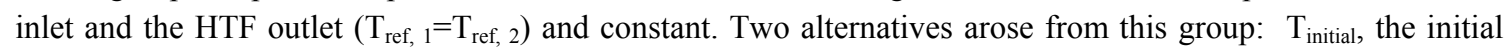
temperature of the storage unit and $\mathrm{T}_{\text {melt }}$, the melting temperature of the PCM.

The second group consists of reference temperatures as single values used for the evaluation of the temperature difference at the inlet and at the outlet $\left(\mathrm{T}_{\text {ref, } 1}=\mathrm{T}_{\text {ref, } 2}\right)$, but with temporary variation. The temperatures that fall into this group are: $T_{\text {mean }}(t)$, the mean temperature of the PCM and $T_{\max }(t)$, the maximum temperature of the PCM (when the discharging process is analysed).

The third group is made up of definitions of reference temperatures differentiated between inlet and outlet and with temporary variation: $T_{\max } / T_{\min } 1 \mathrm{st} P C M$ row $(t)$, where $T_{\max }$ corresponds to the PCM temperature at the inlet $\left(T_{\text {ref, } 1}\right)$ and $T_{\min }$ corresponds to the PCM temperature at the outlet $\left(T_{\text {ref, } 2}\right)$ - in each case close to the HTF; and $\mathrm{T}_{\text {mean }}$ first/last column $(\mathrm{t})$, which is obtained from the mean temperature of the PCM at the inlet $\left(\mathrm{T}_{\text {ref, }, 1}\right)$ and the mean temperature of the PCM at the outlet $\left(\mathrm{T}_{\text {ref, } 2}\right)$.

In this work, the mean UA values estimated were evaluated over the energy exchanged instead of over time (eq. $6)$.

$$
U A_{\text {mean }}=\frac{\int U A \cdot d Q}{Q} \text { (eq. 6) }
$$

In addition, the analytical mean value of the UA [W/K] was estimated according to equation 7 for discharging (solidification) processes to compare it with the UA values obtained in the numerical simulation. Heat convection in the liquid phase of the PCM is neglected and only the heat conduction resistance is considered. $A$ accounts for the contact surface between the PCM encapsulation and the HTF $\left[\mathrm{m}^{2}\right], \alpha$ is the heat convection coefficient between the heat transfer fluid and the PCM encapsulation $\left[\mathrm{W} /\left(\mathrm{m}^{2} \cdot \mathrm{K}\right)\right], \mathrm{k}$ is the $\mathrm{PCM}$ thermal conductivity of the solid phase $[\mathrm{W} /(\mathrm{m} \cdot \mathrm{K})]$ and PCM_thickness is the thickness of the plate (encapsulation) containing the PCM [m].

$U A=\left(\frac{1}{A * \alpha}+\frac{P C M_{-} \text {thickness }}{k * A * 4}\right)^{-1}($ eq. 7)

Finally, the third approach was a parameter of normalized power in relation to the volume (power compactness) and temperature differences (operation temperatures). This parameter is defined in this work as $\dot{Q}_{\text {norm }}$, $\left[\mathrm{W} /\left(\mathrm{m}^{3} \cdot \mathrm{K}\right)\right]($ eq. 8$)$.

$\dot{Q}_{\text {norm }}=\frac{\dot{Q}_{\text {mean }}}{V \cdot \Delta T}($ eq. 8)

Where V is the volume of the storage $\left[\mathrm{m}^{3}\right], \dot{Q}_{\text {mean }}[\mathrm{W}]$ is the mean of the exchanged power using an exchanged energy basis - identical to the procedure for $\mathrm{UA}-$ and $\Delta \mathrm{T}[\mathrm{K}]$ is the temperature difference evaluated in equation 9 with $T_{h \text {,mean }}[\mathrm{K}]$ evaluated in equation 10 . In these equations, $\mathrm{H}_{\mathrm{PCM}}$ and $\mathrm{H}_{\mathrm{HTF}}$ are the corresponding enthalpies $[\mathrm{J}]$ as a function of temperature of the PCM and the heat transfer fluid in the storage unit. This procedure is similar to the one of Pinnau (2009), but with a different definition of $\Delta \mathrm{T}[\mathrm{K}]$. 


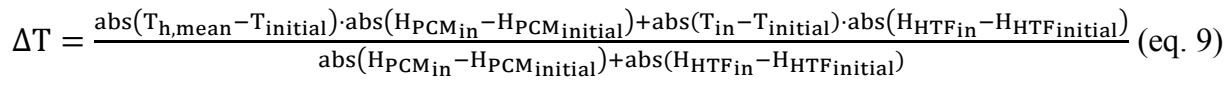

$$
\begin{aligned}
& \mathrm{T}_{\mathrm{h} \text {,mean }}=\frac{\int_{\mathrm{T} \_ \text {initial }}^{\mathrm{T} \text { _in }} H_{\mathrm{PCM}}(\mathrm{T})-H_{\mathrm{PCM}} \text { initial }}{\mathrm{dT}}(\text { eq. 10) }
\end{aligned}
$$

Aiming to assess the suitability of the proposed parameters to compare PCM systems with different configurations and operation conditions, the study on the influence of Biot number, Stefan number, HTF volume and NTU (varied by different mass flows) on the estimated UA and $\dot{Q}_{n o r m}$ is accomplished using a numerical model that describes the thermal performance of a flat plate PCM heat exchanger. It consists of one large plate with a PCM volume of $0.2 \mathrm{~m}^{3}$ and a thickness of $0.1 \mathrm{~m}$. The HTF volume is given in table 2 and the artificial PCM with a melting point of $42{ }^{\circ} \mathrm{C}$ has a constant heat capacity of $2000[\mathrm{~J} /(\mathrm{kg} \cdot \mathrm{K})]$, a thermal conductivity of 1 $[\mathrm{W} /(\mathrm{m} \cdot \mathrm{K})]$ in the design case, a constant density of $1000\left[\mathrm{~kg} / \mathrm{m}^{3}\right]$ and a latent heat of 200000, 100000 or 1 $[\mathrm{J} / \mathrm{kg}]$. The heat transfer coefficient is predefined and independent of the mass flow (except for the validation), but is varied together with the thermal conductivity of the PCM to achieve different Biot numbers. It is important to mention that for all variations the theoretical UA value is identical. In this study, two different initial temperatures and two different HTF were investigated. The use of the numerical model allows for the evaluation of the UA with the aforementioned temperature definitions which are not measured in all the experimental cases available in this research. Furthermore, considerations such as subtracting the thermal effect caused by the initial mass of HTF inside the system can only be faced by numerical simulations. However, the experimental tests are used for the validation of the numerical model. The numerical study on the influence of Biot number, Stefan number (varied by different L), HTF volume and NTU (varied by different mass flows) results in 81 different cases studied for both HTF fluids and initial temperatures. Table 2 shows the range of the parameters varied in the numerical study.

Tab. 2: Parameters varied in the numerical study

\begin{tabular}{llll}
\hline & Variation 1 & Variation 2 & Variation 3 \\
\hline Biot number & 50 & 24 & 8.4 \\
HTF volume in $\mathrm{m}^{3}$ & 0.01 & 0.02 & 0.04 \\
NTU air & 3.05 & 1.53 & 0.76 \\
NTU water & 0.74 & 0.37 & 0.18 \\
Stefan number (solid+liquid), Tinitial $=43^{\circ} \mathrm{C}$ & 0.11 & 0.22 & 22000 \\
Stefan number (solid+liquid), Tinitial $=52^{\circ} \mathrm{C}$ & 0.2 & 0.4 & 40000
\end{tabular}

The resulting standard and mean deviations of the mean UA and $\dot{Q}_{\text {norm }}$ values obtained for the different HTF and different initial temperature were analysed. The lowest standard deviation is considered as the selection criteria for the aimed parameter, which enables the comparison of different systems with different operation conditions. In addition, in the case of mean UA values, the deviation from the analytical value informs about the suitability of the definition to describe the heat transfer process as described in the analytical value. It is worth highlighting that the same main assumptions are made in the analytical definition of UA and in the numerical model. This information will be useful when other geometries will be faced.

\section{Numerical model}

The numerical model is based on a simple quasi-two-dimensional approach and the diffusion in flow direction is neglected. Based on the experimental set-up described in section 1, the simulation domain forms a storage unit with block-shaped PCM plates and rectangular flow channels for the HTF. The governing one-dimensional equation for the PCM is

$\rho c_{a p p} \frac{\partial T}{\partial t}=\lambda \frac{\partial^{2} T}{\partial y^{2}}+q_{\alpha}($ eq. 11$)$ 
and the one for the HTF is

$\rho c \frac{\partial T}{\partial t}=u \frac{\partial T}{\partial x}+q_{\alpha}+q_{\text {loss }}$ (eq. 12).

The latent heat of the PCM is integrated in the apparent heat capacity $c_{a p p}$ with the help of an error function (see Rösler and Brüggemann (2011)) and $q_{\alpha}$ is used to account for the heat transfer between the PCM and the HTF. Heat losses, which are taken into account by $q_{\text {loss }}$ are only considered for the comparison with the experimental results. A channel wall is not explicitly simulated but it is integrated in the heat transfer coefficient for the comparison with the experiments and the heat capacity of the channel wall as well as the container is added to the HTF in this case. The discretization of equations 11 and 12 is based on the Finite Volume Method and each HTF cell is connected to the first cell of one column of PCM cells. The numerical model is implemented in MATLAB Simulink by means of so called Level 2 C MEX S-functions. No correction and iteration of the temperature and enthalpy field is performed and therefore it was checked if the strong temperature dependency of $c_{a p p}$ is captured by the applied Simulink solver (ode23tb) for stiff problems. For this purpose, the model was validated against the analytical solution of the Stefan problem. Here it was seen that a mesh resolution of 20 nodes in y-direction in the PCM will lead to a maximum relative deviation (i. e. the error in the temperature in relation to the temperature span of the problem) of the numerical results from the analytical solution of about $2 \%$, which is acceptable. In addition, the basis of the numerical model was also verified previously against CFD results from ANSYS Fluent ( https://www.ansys.com/products/fluids/ansysfluent).

Finally, the numerical model was validated against the experimental results of system A described in section 2.1

For this purpose, one water reservoir was added at the inlet and one at the outlet of the original numerical model. Before comparing the numerical results to the experimental ones, a mesh independency study was performed. Table 3 shows the absolute mean and maximum deviations of the outlet HTF temperature for different mesh in relation to the finest mesh studied. As a compromise between computing time and accuracy, the $100 \times 20$ grid was chosen for all following simulations and for the simulations regarding the experiments the reservoirs were implemented with 10 cells each. Comparing the numerical results with the experimental ones revealed the following. The mean of the absolute deviation of the outlet temperature is $0.16 \mathrm{~K}$ and the corresponding maximum deviation is $2.23 \mathrm{~K}$. In addition, the deviation of the thermal energy released was determined and will be presented in relation to the maximum energy released in the experiment. Following this approach, the mean and maximum absolute deviation of the thermal energy released are $3.26 \%$ and $4.79 \%$, respectively. Considering the uncertainties of the given material properties and the ones of the determination of the heat losses, the results represent a satisfactory validation.

Tab. 3: Absolute mean and maximum deviations of the outlet HTF temperature compared to the finest mesh.

\begin{tabular}{|c|c|c|}
\hline $\begin{array}{c}\text { Mesh size in } \mathbf{x} \text { - and y-direction } \\
\text { and the reservoirs }\end{array}$ & Mean deviation in K & Max deviation in K \\
\hline $120 \times 30+20 \times 2$ & 0 & 0 \\
\hline $100 \times 20+10 \times 2$ & 0.0086978 & 0.02729 \\
\hline $60 \times 10+10 \times 2$ & 0.0286078 & 0.07805 \\
\hline $20 \times 5+5 \times 2$ & 0.0792472 & 0.18425 \\
\hline
\end{tabular}

\section{Results}

Capacity

The technical performance of the involved PCM components were estimated according to the defined parameters and compared among each other. As an illustrative example, the obtained capacity parameters evaluated for the studied systems (storage capacity and the storage density) are presented in Table 4, along with the main characteristics of the used heat transfer fluids. 
Tab. 4: Heat transfer fluid, mass flow, storage capacity and storage density of 2 PCM systems

\begin{tabular}{|l|l|l|}
\hline & System A & System B \\
\hline HTF mass flow $(\mathrm{kg} / \mathrm{min})$ & 2.4 & 1.68 \\
\hline HTF fluid & water & air \\
\hline Energy storage capacity of the system $(\mathrm{MJ})$ & 2.95 & 24.4 \\
\hline Energy storage density $\left(\mathrm{MJ} / \mathrm{m}^{3}\right)$ & 78 & 44 \\
\hline
\end{tabular}

\section{Power}

The initial attempt of the power performance of the system was to compare the exchanged heat rate over time (Figure 1). As shown in table 4, the studied systems have different sizes and operation conditions which are reflected in the power curves shown in figure 1. An example of the different curves with two different inlet temperatures of the HTF for one system is also shown for system B.

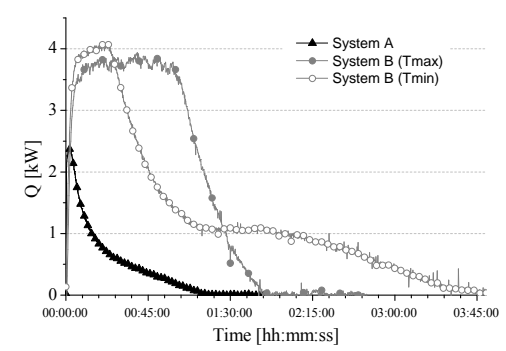

Fig. 1: Power evolution over time of the evaluated PCM systems

As explained in section 2, aiming to find parameters which enable the comparison of performance independently of size and operation conditions, the overall heat exchange coefficient over the heat exchange surface and $\dot{Q}_{\text {norm }}$ parameters are proposed.

To find the proper UA estimation methodology for PCM heat exchangers, two additional evaluation considerations have been examined. The first one is the range considered in the evaluation (stop criteria) and the second one is the initial heat capacity of the HTF in the storage system at the initial temperature. In this work, the influence of the stop criteria for the evaluation is studied comparing results applying a stop criterion of $99 \%$ and $90 \%$ of transfered heat in relation to a complete discharging.

The influence of the stop criteria was analized for the different reference temperatures and the 81 cases simulated.

The results in figure 2 show that the mean UA values estimated over the exchanged energy instead of an estimation over time have a weak dependency on the stop criterion. Additional tests not shown here revealed that UA values evaluated over time have a strong dependency on the stop criterion. Therefore, the mean UA value and $\dot{Q}_{\text {norm }}$ used for comparison in all the cases in this work correspond to the mean over the exchanged energy and a stop criteria of $99 \%$ of the total exchanged energy.

As it can be seen in figure 3, the HTF mass amount within the system (which is at the initial storage temperature at the beginning of the experiment) can noticeably increase the initially exchanged thermal energy values. If the thermal capacity of the HTF is not negligible compared to the one of the PCM, the outlet HTF temperatures registered at the beginning are not influenced by the heat release of the PCM as long as a through flow of the HTF has not taken place. Therefore, the outlet temperatures are in theory temperatures of the storage unit in the beginning of the experiment, which lead to an ill-defined $\Delta \mathrm{T}_{\mathrm{m}}$. This work has analyzed and considered these phenomena when water is used as HTF - for air this effect was negligible due to the low volumetric heat capacity of air. In the following results, the mean UA values and $\dot{Q}_{\text {norm }}$ with water as HTF are analysed subtracting (cutted) and not subtracting (uncutted) this thermal capacity of the HTF. 


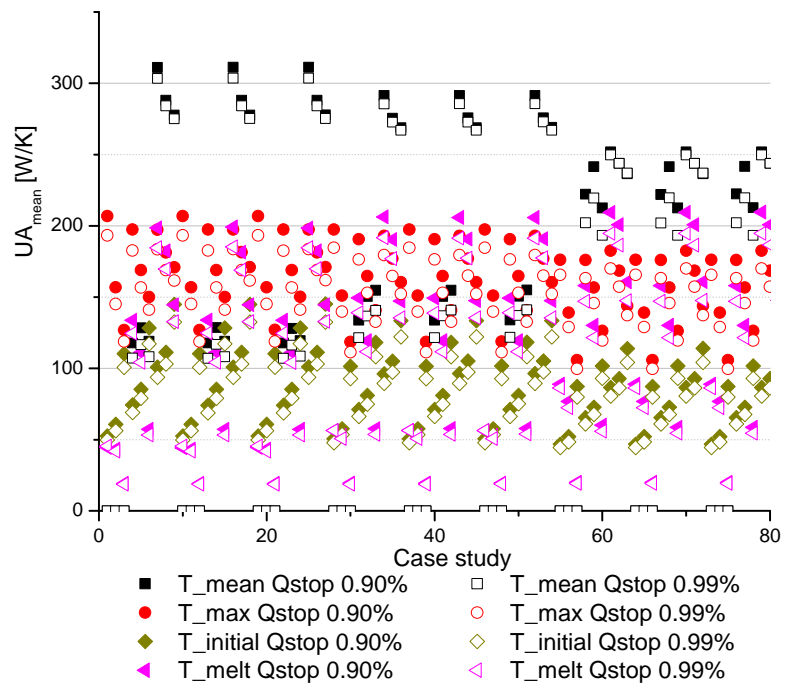

Fig. 2. : Dependency on the stop criteria of mean UA values estimated over exchanged energy in the 81 case studies simulated for air as HTF fluid, an initial temperature of $52{ }^{\circ} \mathrm{C}$ and temperatures Tref evaluated as $\mathbf{T}_{\text {melt. }}$

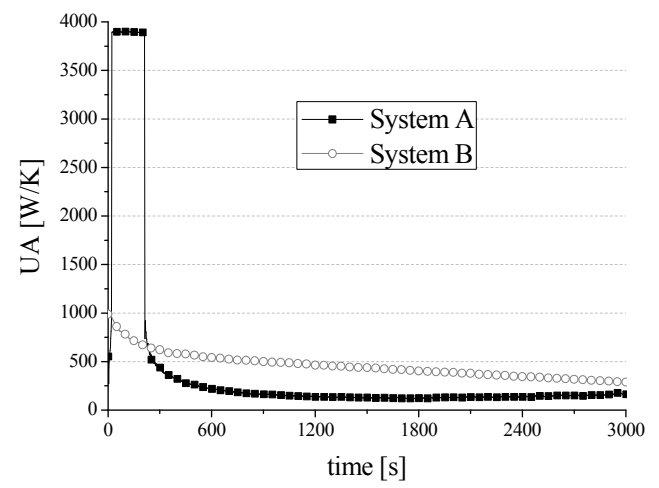

Fig. 3: Experimental UA [W/K] values over time for the two HTF studied: water (System A) and air (System B)

The estimated UA values obtained in the numerical model are shown in figures 4 to 6.

Figure 4 shows the mean UA values obtained for air as HTF. As explained in section 2, the parameter variations of Biot number, HTF volume, NTU and Stefan number result in 81 cases per initial temperature and HTF.

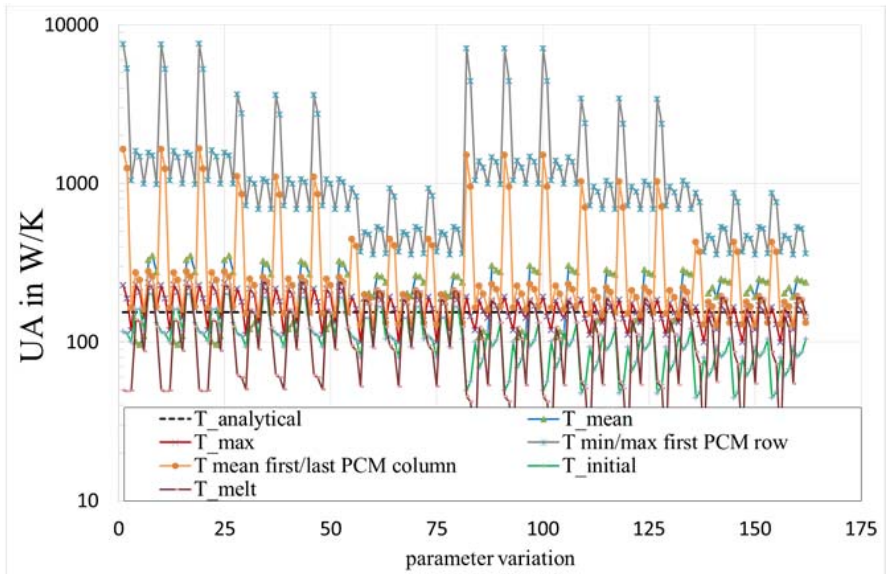

Fig. 4: UA mean values obtained with the proposed temperatures for Tref for air as $\mathrm{HTF}$ for $\mathrm{T}$ initial $=43^{\circ} \mathrm{C}$ (parameter variation from 1 to 81) and $\mathrm{T}$ initial $=52^{\circ} \mathrm{C}$ (parameter variation from 82 to 162) 

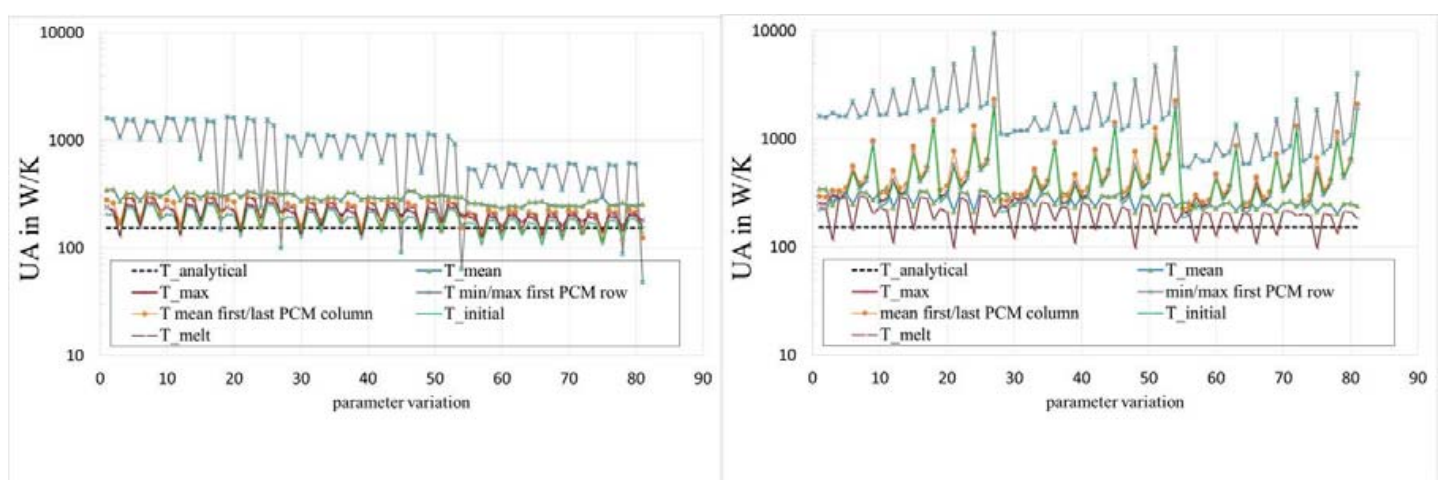

Fig. 5: UA mean values obtained with the proposed Tref for water as HTF and T initial $43^{\circ} \mathrm{C}$ : cutted (left) and uncutted (right)
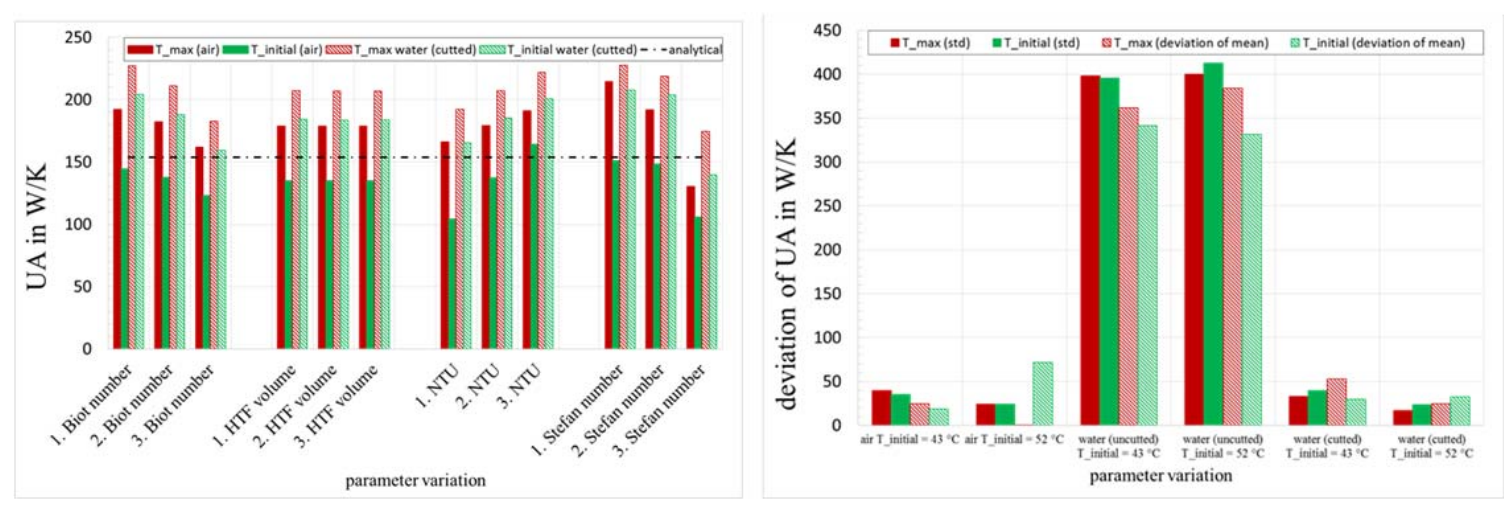

Fig. 6: UA mean values obtained for the parameter variations of Biot number, HTF volume, NTU and Stefan number for air and water as HTF using $T_{\max }$ and $T_{\text {initial }}$ as temperatures $T_{\text {ref. }}$

The estimated $\dot{Q}_{\text {norm }}$ obtained are shown in figures 7 and 8 . Figure 7 shows the obtained $\dot{Q}_{\text {norm }}$ values over the parameter variations of Biot number, HTF volume, NTU and Stefan number for air and water as HTF using $\mathrm{T}_{\max }$ and $\mathrm{T}_{\text {initial }}$ as temperatures $\mathrm{T}_{\text {ref. }}$. The estimated $\dot{Q}_{\text {norm }}$ over the normed thermal capacity flow are shown in figure 8. As it was seen that the cutted evaluation gives less reasonable results than the uncutted one only the uncutted results are presented.

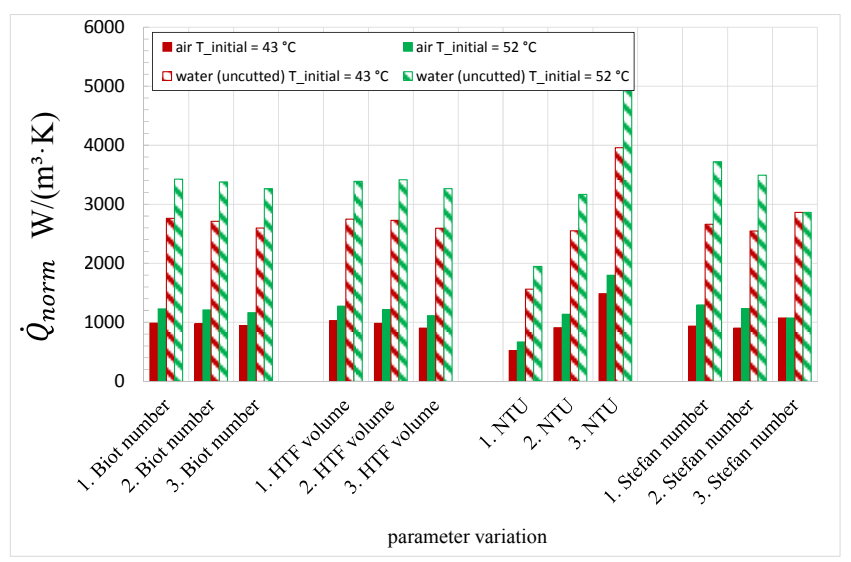

Fig. 7: $\dot{Q}_{\text {norm }}$ values obtained for the parameter variations of Biot number, HTF volume, NTU and Stefan number for air and water as HTF 


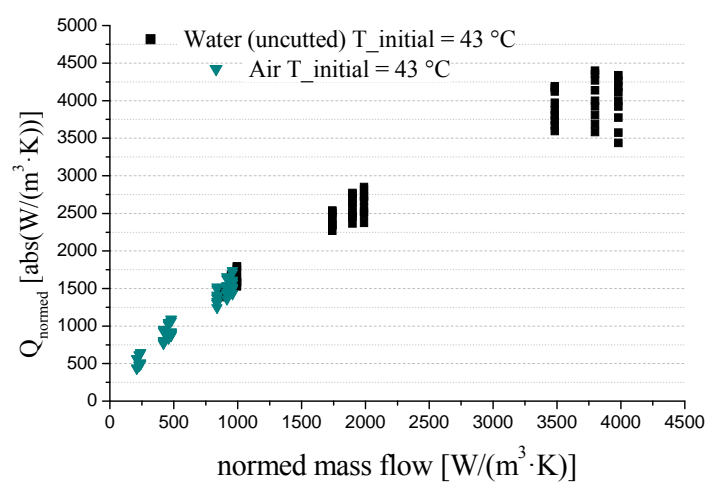

Fig. 8: $\dot{Q}_{\text {norm }}$ values obtained over normed HTF thermal capacity flow $\left(\frac{\dot{m} \cdot c}{V}\right)$ for air and water as $\mathrm{HTF}$ and $\mathrm{T}$ initial $43^{\circ} \mathrm{C}$.

\section{Discussion}

Table 4 shows the proposed capacity parameters evaluated for the studied systems. It can be observed that the aimed information (energy that can be stored/released and total volume needed) is provided and systems can be compared.

As shown in Figures 4 to 6 the temperatures used as reference temperatures $T_{\text {ref }}$ in the evaluation of the logarithmic mean temperature $\overline{\Delta T}_{m}$ to estimate the UA values lead to differences among each other higher than $500 \%$. Moreover, reference temperatures without differentiation between inlet and outlet are easily inconsistent with the evaluation of the logarithmic mean temperature difference and present mathematical lack of definition when the temperature level of the HTF at the inlet and at the outlet in relation to the reference temperature have different positions resulting in a negative value of the ratio within the logarithm. That is the case with $T_{\text {melt }}$ and $\mathrm{T}_{\text {mean }}(\mathrm{t})$. Furthermore, these two definitions of reference temperatures show high deviations in estimated mean UA values, a strong dependency on the mass flow, but they are not so much influenced by the type of HTF. The third group of proposed definition of reference temperatures shows the higher deviation of estimated mean UA values. $T_{\max } / T_{\min } 1$ st PCM row $(\mathrm{t})$ present deviations of on average about $700 \%$ to the analytical UA value and the UA estimations with the other reference temperatures. $T_{\text {mean }}$ first/last PCM column ( $t$ ) shows the second highest deviations with more than $100 \%$ on average.

The use of $T_{\text {initial }}$ gives acceptable results for both HTF, water and air, with deviations in the order of $20 \%$ to $30 \%$. As shown in figure 5 , when $T_{\text {initial }}$ is used as reference temperature and the HTF presents considerable thermal capacity inside the system at the beginning of the experiment, the effect of the thermal capacity should be subtracted for a proper evaluation of the mean UA value.

The lowest deviation on average in estimated mean UA values for both HTF result for the definition of $T_{\max }(\mathrm{t})$ as reference temperature for discharging processes. These deviations are in the range of $13-27 \%$ for air as HTF and $17-35 \%$ for water (Figure 6). It is worth highlighting that in case of water as HTF, the proper mean UA evaluation with $T_{\max }(\mathrm{t})$ relies on the cutting process to subtract the initial thermal capacity of the HTF from the registered data.

The mean UA estimation evaluated with either $T_{\max }(\mathrm{t})$ or $T_{\text {initial }}$ as reference temperatures is influenced by the mass flow/NTU and the normed melting enthalpy/Stefan number. These influences are noticeable for all tested NTU and become significant for a change of the Stefan number from 0.22 and 0.4 to a practical pure sensible case with a Stefan number of 22000 and 40000 for initial temperatures of $43{ }^{\circ} \mathrm{C}$ and $52{ }^{\circ} \mathrm{C}$, respectively (Figure 6). The Biot number generally shows a low influence and when air is used as HTF, the influence is smaller than for water. The normed $\dot{Q}_{\text {norm }}$ parameter shows a low dependency on the design and operation conditions except for the mass flow/NTU (Figure 7). Therefore it is recommended to plot it over a normed thermal capacity flow as depicted in figure 8 . The normed $\dot{Q}_{n o r m}$ parameter intrinsically alleviates the effect of the thermal capacity of the HTF being able to be estimated directly from the experimental results. Then for the normed $\dot{Q}_{\text {norm }}$ estimation the need of known parameters is reduced to $T_{\text {initial }}$, Volume, HTF inlet and outlet temperature and mass flow as well as the enthalpy/temperature curve of the PCM. 


\section{Conclusions}

The technical performance description of heat exchangers used as thermal energy storage systems involving liquid to solid phase change processes should consider capacity and power parameters. While capacity parameters are commonly found in literature, normalized power-related parameters are still required to design and compare new systems. The conventional heat exchanger analyses ( $\varepsilon-N T U$, LMTD) are not directly suitable because of the transient nature of the phase change.

Regarding capacity, two parameter definitions were evaluated in this paper: Energy storage capacity of the system and Energy storage density. These two parameters were suitable to inform on the thermal energy that can be stored and released by the system and the total volume that the system requires.

Concerning power parameters, the exchanged heat rate over time depends on size and operation conditions of the TES system. Two alternative parameters were studied and depicted recommendations for its evaluation were proposed: i) the estimation of mean UA values ii) the estimation of a normed parameter $\dot{Q}_{\text {norm }}$.

Aiming to estimate the mean UA parameter useful to compare different systems and reduce the influence on operation conditions, the recommended procedure would consist of: i) evaluating the UA value from the exchanged energy divided by the logarithmic mean temperature difference, using the maximum temperature of the storage when a discharging process is analyzed, $\mathrm{T}_{\max }(\mathrm{t})$, as reference temperature. If the information on temperature distribution inside the system is not available, the initial temperature of the storage system would be the best alternative to $T_{\max }(t)$ ii) when water is used as HTF, the power delivered by the system during the period of time when the initial thermal capacity of the HTF inside the system is flowing out of the system should be subtracted and not taken into consideration when the mean UA value is evaluated iii) use of exchanged energy basis for the mean UA evaluation instead of time basis, which also noticeably reduces the influence of the stop criterion (transferred heat in relation to exchanged energy in a complete discharging). The obtained mean UA values can be normed to volume of storage when different sizes of TES are to be compared.

The recommended procedure to estimate the normed $\dot{Q}_{n o r m}$ parameter is: i) evaluating the mean exchanged power $\left(\dot{\mathrm{Q}}_{\text {mean }}\right)$ using an exchanged energy basis ii) evaluating the temperature difference according to equation 9 and equation 10 iii) evaluating the $\dot{Q}_{n o r m}$ parameter according to equation 8 . Note that when water is used as $\mathrm{HTF}$, the power delivered by the system can be considered in the evaluation of the normed parameter $\dot{Q}_{n o r m}$ without any subtraction of the initial thermal capacity of the HTF inside the system.

Future research effort is required in order to validate the proposed methodology for different geometries wider range of parameters, charging (melting) and different heat exchanger configurations.

\section{Acknowledgments}

This work was developed in the frame of the research project ENE2017-87711-R, partially funded by the Spanish Government (Energy Program), the Government of Aragon (Ref: T55-17R), Spain, and the EU Social Fund (FEDER Program 2014-2020 "Building Europe from Aragon"). The authors from the UPV/EHU want to acknowledge the funding from the Spanish Government by the research project: RTI2018-099557-B-C22 Sistemas de almacenamiento termico latente basado en polioles: diseño y prototipado.

\section{References}

Amagour, M. E. H., Rachek, A., Bennajah, M. \& Touhami, M. E. (2018) Experimental investigation and comparative performance analysis of a compact finned-tube heat exchanger uniformly filled with a phase change material for thermal energy storage. Energy Conversion and Management 165:137-151.

Belusko, M., Halawa, E. \& Bruno, F. (2012) Characterising PCM thermal storage systems using the effectiveness-NTU approach. International Journal of Heat and Mass Transfer 55(13-14):3359-3365.

Brüggemann, D., König-Haagen A., Kasibhatla R. R., Höhlein S., Glatzel U., Völkl R., and Agarkov N. (2017) Entwicklung makroverkapselter Latentwärmespeicher für den Transport von Abwärme (MALATrans): Abschlussbericht: Laufzeit: 01.07. 2013 bis 31.12. 2016. Universität Bayreuth, Lehrstuhl für Technische Thermodynamik und Transportprozesse (LTTT) 
Delgado, M., Lazaro, A., Mazo, J., Penalosa, C., Dolado, P. \& Zalba, B. (2015) Experimental analysis of a low cost phase change material emulsion for its use as thermal storage system. Energy Conversion and Management 106:201-212.

Fornarelli, F., Camporeale, S. M. \& Fortunato, B. (2019) Simplified theoretical model to predict the melting time of a shell-and-tube LHTES. Applied Thermal Engineering 153:51-57.

Gao, T. Y., Geer, J. \& Sammakia, B. (2015) Development and verification of compact transient heat exchanger models using transient effectiveness methodologies. International Journal of Heat and Mass Transfer 87:265278.

Groulx, D. (2018) The rate problem in solid-liquid phase change heat transfer: efforts and questions toward heat exchanger design rules In Proceedings of Proceedings of the 16th International Heat Transfer Conference IHTC-16.

Ismail, K. A. R. \& Goncalves, M. M. (1999) Thermal performance of a pcm storage unit. Energy Conversion and Management 40(2):115-138.

Kalapala, L. \& Devanuri, J. K. (2018) Influence of operational and design parameters on the performance of a PCM based heat exchanger for thermal energy storage - A review. Journal of Energy Storage 20:497-519.

Ma, Z., Li, M.-J., Yang, W.-W. \& He, Y.-L. (2018) General performance evaluation charts and effectiveness correlations for the design of thermocline heat storage system. Chemical Engineering Science 185:105-115.

Pinnau S. (2009) Strömungs- und kältetechnische Optimierung von Latentkältespeichern, Abschlussbericht, Universität Dresden

Roesler, F. \& Brueggemann, D. (2011) Shell-and-tube type latent heat thermal energy storage: numerical analysis and comparison with experiments. Heat and Mass Transfer 47(8):1027-1033.

Rojas, E., Bayon, R., Adinberg, R., Valenzuela, L., Laing, D., Py, X., Bauer, T. \& Fabrizi, F. (2011) Definition of standardised procedures for testing thermal storage prototypes for concentrating solar thermal plants. WP 15 report, SFERA project available on line at http://sfera.sollab.eu/index.php?page=downloads_jra reports $(17 / 07 / 2019)$.

Romani, J., Gasia, J. \& Cabeza, L. F. (2018) Definitions of technical parameters for thermal energy storage (TES). Available on line from International Energy Agency, ECES, Annex 30: Thermal Energy Storage for cost effective energy management \& CO2 mitigation. https://www.eces-a30.org/ (17/07/2019).

Zondag, H. A., De Boer, R., Smeding, S. F. \& Van Der Kamp, J. (2018) Performance analysis of industrial PCM heat storage lab prototype. Journal of Energy Storage 18:402-413.

ANSYS Fluent software: https://www.ansys.com/products/fluids/ansys-fluent (17/07/2019)

International Energy Agency, SHC-ECES, Joint Annex33/Task 58 Materials \& components for Thermal Energy Storage, http://task58.iea-shc.org/ (17/07/2019) 